\title{
A multidisciplinary approach is mandatory to solve complex crimes: a case report
}

\author{
Michela Ferrara ${ }^{1 \dagger}$, Francesco Sessa $^{1{ }^{* \dagger}} \mathbb{D}$, Marcello Rendine ${ }^{1}$, Lorenzo Spagnolo ${ }^{1}$, Stefania De Simone ${ }^{1}$, Irene Riezzo ${ }^{1}$, \\ Pietrantonio Ricci ${ }^{1,2}$, Natascha Pascale ${ }^{1}$, Monica Salerno ${ }^{3}$, Giuseppe Bertozzi ${ }^{1 \dagger}$ and Francesca Maglietta ${ }^{1+}$
}

\begin{abstract}
Background: Self-defense is legitimate both in common law and in civil law systems. Nevertheless, there remains the age-old question for the prosecutor to identify the limit between the righteous self-defense and the self-defense with excessive force. In these cases, the gathering of all evidence by a forensic multidisciplinary team is essential to provide the necessary data for the prosecutor's evaluation.

Case presentation: The case of a 55-year-old man who was killed in front of his neighbor's house is described. The prosecutor alerted the forensic team, classifying the crime as a gunshot homicide. The neighbor immediately admitted his responsibility as self-defense. Moreover, the relatives of the victim told a different version of the story, assuring that the neighbor had killed him for futile motivations. For these reasons, the prosecutor established further investigations, such as autopsy, the K-9 unit exploration, and alerting the forensic biologist for analysis.

Conclusions: This case aims to highlight the teamwork of multidisciplinary forensic expertise to solve complex cases; moreover, combining ultra-specialist forensic activities, such as the K-9 unit, it is possible to collect all the evidence to submit to the prosecutor for the formulation of judgment.
\end{abstract}

Keywords: Forensic canine unit, Genetic analysis, Touch DNA, Crime scene reconstruction

\section{Background}

In the Italian law system, legitimate defense is contemplated in article 52 of the penal code: “... if someone legitimately presents in one of the places indicated therein uses a legitimately held weapon or other suitable means in order to defend: a) one's own or others' safety; b) the goods of one's own or others, when there is no desistence and there is a danger of aggression ...." In English law, a similar principle is proposed in the case "Beckford v R (1988)": "A defendant is entitled to use reasonable force to protect himself, others for whom he is responsible and his property." However, notwithstanding its legitimacy, there remains the age-old question for the prosecutor to identify the limit between righteous self-defense and self-defense with excessive force. In these cases, the gathering of all evidence by a forensic

\footnotetext{
* Correspondence: francesco.sessa@unifg.it

Giuseppe Bertozzi and Francesca Maglietta shared the last authorship.

${ }^{+}$Michela Ferrara and Francesco Sessa contributed equally to this work.

${ }^{1}$ Department of Clinical and Experimental Medicine, Section of Legal

Medicine, University of Foggia, Viale Pinto, 71122 Foggia, Italy

Full list of author information is available at the end of the article
}

multidisciplinary team is essential to provide the necessary data for the prosecutor's evaluation.

In the last few years, a multidisciplinary approach to the crime scene is believed an essential investigation tool (Bilge et al. 2003; Kahana et al. 2005; Harding et al. 2011; Pomara et al. 2015; Maglietta et al. 2017; Sessa et al. 2018); in this manner, the gathering of evidence is guaranteed, clarifying the principal aspects of the facts.

The forensic team involved in crime scene investigations, especially in cases where it may be necessary to identify hidden objects or invisible traces, is increasingly integrated with the use of trained dog units to search for decomposing human odors. The cadaver dogs are used to detect and localize hidden human remains or fluids (blood, urine, etc.) due to the high perception of the canine olfactory system and the relative facility with which dogs can be trained and managed (Riezzo et al. 2014).

The dogs, at first, were used only as a hunting tool, only later were they used as an instrument of detecting by many governments and law enforcement agencies. Current employment of scent dogs includes the detection of drugs, explosives, accelerants, humans (alive and 
dead), agricultural products, money, melanomas, and pests (Lorenzo et al. 2003).

The bailiwick of human remains detector (HRD) canines, also known as cadaver dogs, is the search and recovery; these units are coached to identify living humans, often in open and wild space or disaster settings (DeGreeff et al. 2012).

Search and rescue in mass disasters is frequently very difficult as well as in searching for missing persons, particularly when they are dead. In these cases, "human odor" (linked with specific characteristics of each person) passes to "dead human odor" (a dead body, specifically a human corpse, has a rank and pungent smell); for these reasons, it was very difficult for dogs to evaluate correctly all crime scenes searching for the right scent trace (Marchal et al. 2016).

For this reason, dogs are trained to locate human remains, including whole bodies, body parts, tissues, blood, bone, and decomposition fluids. Several studies have focused on the ability of cadaver dogs to locate extremely small or aged scent sources. However, the performance of the dogs can be influenced by practice, familiarity with the odor source, and ambient conditions (Cablk and Sagebiel 2011). For the training, the instructor can use human bone, gauze that has been soaked in decomposition fluid, blood, adipocere, grave dirt, and articles or clothing previously in contact with remains (Komar 1999), because in real scenarios, dogs can search for a range of odors, from fresh and putrefied bodies to ancient skeletal remains.

However, the limits of the use of cadaver dogs are the absence of standardized procedures in their training and the admissibility of human "odor mortis" discrimination in courts (DeGreeff et al. 2012; McEwen and McDonough 2016). With the purpose of identifying "standard training technique," many studies have been performed, using human tissues and their degradation, analyzing reactive oxygen species, autolysis, microorganisms, or scavengers. Moreover, it is particularly interesting the attempt to identify the specific production of volatile organic compounds (VOCs) (Rendine et al. 2018).

Nevertheless, it is very important to collect and preserve the evidence following the well-established protocols for forensic services, in order to preserve the evidence, both avoiding contamination and assuring the respect of "chain of custody" (Butler 2011).

The purpose of this report is to underline the importance of a multidisciplinary forensic team during crime scene investigations; the careful collection and analysis of evidence could be considered essential for crime resolution. Indeed, in this case, the activity of the K-9 (canine) unit and the following genetic analyses, supplied in a decisive manner by the forensic pathologist, helped the prosecutor to classify this manslaughter as self-defense.

\section{Case presentation}

The case of a 55-year-old man killed in front of his neighbor's house is described. The prosecutor alerted the forensic team, classifying the crime as a gunshot homicide. On the crime scene, the man was found supine in a large pool of blood, on a sidewalk. Two bullet cases were collected at the crime scene: one at $370 \mathrm{~cm}$ from the corpse on the sidewalk and the other one near the steps in front of the entrance door of the building, at $390 \mathrm{~cm}$ from the corpse. The door of the house was open, and the lower panel of this door was broken. Both the window of this house and the windscreen of a car, parked nearby, were broken.

The neighbor admitted immediately his responsibility advocating the self-defense principle, declaring that he had killed the man because the latter had attacked him first with a golf club used to smash his car windscreen and the house door panel. The investigators did not believe this reconstruction because no golf club was found on the crime scene. Moreover, the relatives of the victim said that the murderer had killed him for futile motivations. For these reasons, according to the forensic pathologist's advice, the prosecutor called for further investigations: autopsy, the K-9 unit exploration, and alerting the forensic biologist.

\section{The external examination}

The external examination of the body showed the presence of three gunshot wounds: the first, on the fourth left intercostal space, linear and with finely frayed and everted edges (exit hole); the second, on the left upper abdominal quadrant, round-shaped with frayed and inverted margins (entrance hole); and the third, on the right dorsal region, round-shaped with frayed and inverted margins (entrance hole).

\section{Autopsy findings}

Computed tomography was performed $24 \mathrm{~h}$ later showing bilateral hemothorax, hemopericardium, vanishing aorta sign (Cafarelli et al. 2018), and a metal-density foreign body in the subcutaneous fat of the right gluteus. The following autopsy examination revealed that one bullet passed through the heart (Fig. 1). Moreover, $300 \mathrm{cc}$ of blood in the pericardial cavity, $650 \mathrm{cc}$ of blood in the left pleural cavity, and $1000 \mathrm{cc}$ of blood in the right pleural cavity were found. A retained bullet was confirmed in the adipose tissue surrounding the right gluteus maximus. The cause of death was attributed to hypovolemic shock from multiple lesions of the heart and the thoracic aorta. Multiple lesions of the small intestine were also 


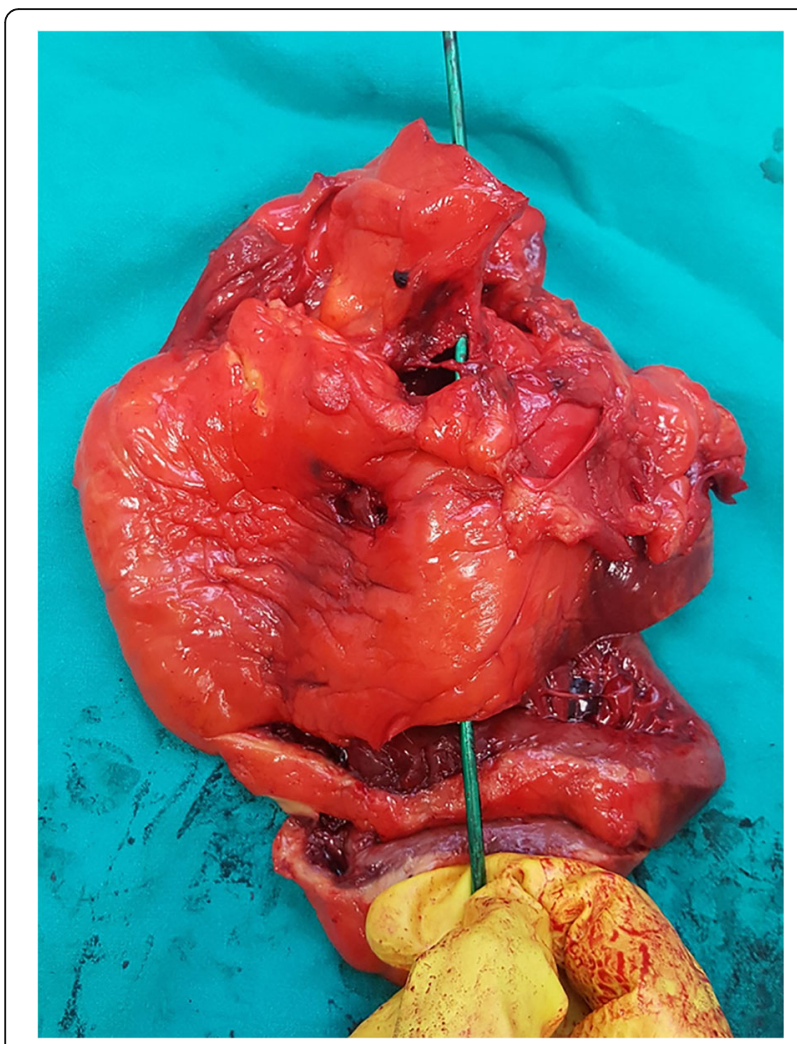

Fig. 1 Heart of the victim. The probe indicates the bullet trajectory

described. Histochemical analysis of skin samples surrounding the entrance gunshot wounds showed no presence of sodium rhodizonate granules, consistent with a firing distance greater than $40 \mathrm{~cm}$.

\section{K-9 unit searches}

The victim's family denied the presence of the golf club, even if some witnesses told to the prosecutor that the victim's son had removed it from the crime scene. A new inspection with the K-9 unit, composed of two dogs trained to detect cadaveric blood traces, was performed. After several minutes, the golf club was found buried in a field in front of the victim's house (Fig. 2).

\section{Medical-legal physical examination performed on the murderer}

The clinical examination performed on the murderer showed the presence of two injuries, one on the head and the other one on the left leg, both ribbon-shaped, with irregular, finely jagged and slightly diastased margins, consistent with wounds produced by a blunt body, with a compression and traction mechanism. After the finding of the golf club, the pathologist described a compatibility of the lesions with golf club blows.

\section{Genetic analysis}

DNA extraction was performed following the QIAmp ${ }^{\circ}$ DNA Investigator Kit protocol (QIAGEN Vic, AUS). The concentration of all DNA extracted was determined with the use of the Quantifiler Duo DNA Quantification Kit (Applied Biosystems), according to the manufacturer's guidelines. Duplicate quantifiler standards ranging from 50 to $0.023 \mathrm{ng} / \mu \mathrm{L}$ and duplicate negative controls were processed in tandem with the reactions. Both reactions were carried out on the ABI PRISM 7500 Sequence Detection System (Applied Biosystems). All samples were amplified with the Identifiler Plus Amplification Kit (Applied Biosystems).

The first step was performed comparing the DNA profile of the guilty man (obtained with a buccal swab) with the blood traces collected on the head of the golf club, demonstrating a perfect match.

Moreover, the adhesive tape technique was utilized to collect trace DNA on the golf club grip with the

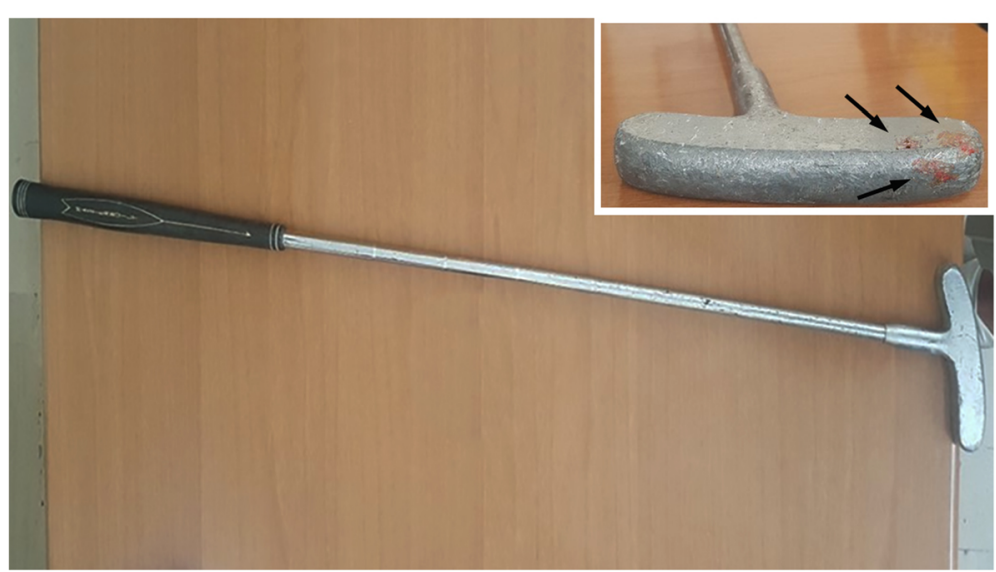

Fig. 2 The golf club used by the victim to attack the neighbor. It was concealed by the relatives but it was discovered by the K-9 unit. In the inset, the presence of biological traces (blood) is highlighted 
aim of obtaining the "touch DNA" of the victim, demonstrating that he was the last handler of the golf club. The "adhesive tape" lifting technique was applied because it is quick and straightforward, even if the DNA extraction is slightly challenging due to the stickiness, rigidity, and size of the tape (Forsberg et al. 2016). The "touch DNA" profile was compared with the victim's DNA typing, obtained with a tissue (spleen) taken during autopsy. The profile comparison showed a compatibility with the victim's DNA profile (Fig. 3a, b). All profiles are summarized in Table 1 .
Indeed, even if there are three extra peaks (marked in red in Table 1), considering the quantity of DNA obtained from sampling the golf club grip, this could be interpreted as allelic "drop in." For the other loci, a perfect match was reported.

\section{Ballistic investigations}

The ballistic evidence collected during the judicial inspection and the autopsy were examined and compared with the firearm given by the murderer. The bullets were compatible with the weapon and were the same as the
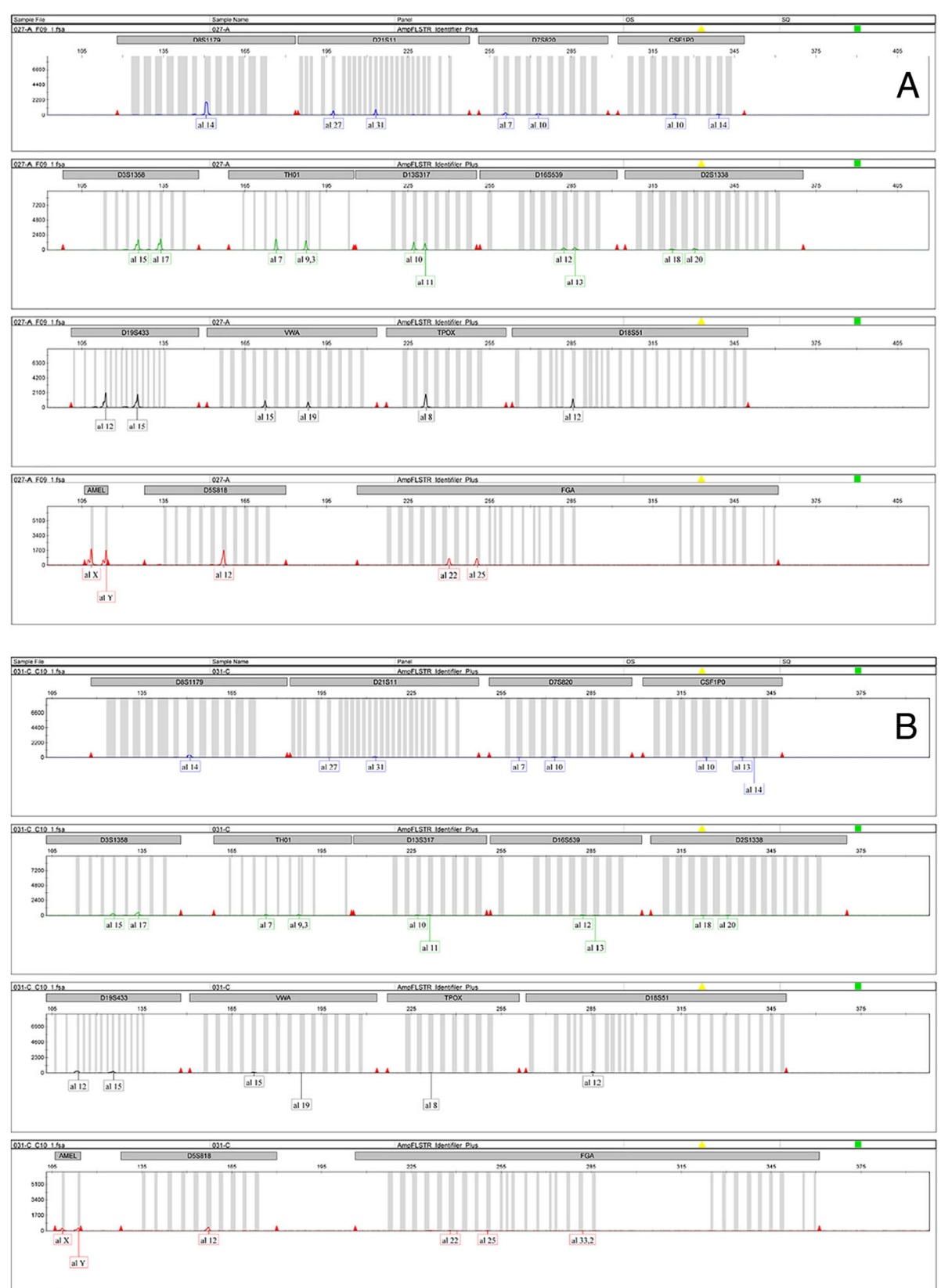

Fig. 3 The reference profile of the victim (a) was compared with the profile obtained with adhesive tape (b) 
Table 1 STRs obtained analyzing all samples. The extra-peaks are indicated in red

\begin{tabular}{|c|c|c|c|c|}
\hline STR & $\begin{array}{l}\text { Victim profile } \\
\text { (spleen tissue) }\end{array}$ & $\begin{array}{l}\text { Touch DNA profile } \\
\text { (sampled on golf club grip) }\end{array}$ & $\begin{array}{l}\text { Murderer profile } \\
\text { (buccal swab) }\end{array}$ & $\begin{array}{l}\text { Blood stain } \\
\text { (sampled on golf club head) }\end{array}$ \\
\hline D8S1179 & $14 / 14$ & $14 / 14$ & $14 / 15$ & $14 / 15$ \\
\hline D21S11 & $27 / 31$ & $27 / 31$ & $30 / 33.2$ & $30 / 33.2$ \\
\hline D7S820 & $7 / 10$ & $7 / 10$ & $8 / 11$ & $8 / 11$ \\
\hline CSF1PO & $10 / 14$ & $10 / 14(13)$ & $10 / 12$ & $10 / 12$ \\
\hline D3S1358 & $15 / 17$ & $15 / 17$ & $16 / 16$ & $16 / 16$ \\
\hline $\mathrm{THO} 1$ & $7 / 9.3$ & $7 / 9.3$ & $7 / 9.3$ & $7 / 9.3$ \\
\hline D13S317 & $10 / 11$ & $10 / 11$ & $8 / 12$ & $8 / 12$ \\
\hline D16S539 & $12 / 13$ & $12 / 13$ & $11 / 12$ & $11 / 12$ \\
\hline D2S1338 & $18 / 20$ & $18 / 20$ & $17 / 17$ & $17 / 17$ \\
\hline D19S433 & $12 / 15$ & $12 / 15$ & $13 / 13.2$ & $13 / 13.2$ \\
\hline VWA & $15 / 19$ & 15/19 (18) & $16 / 16$ & $16 / 16$ \\
\hline TPOX & $8 / 8$ & $8 / 8$ & $9 / 11$ & $9 / 11$ \\
\hline D18S51 & $12 / 12$ & $12 / 12$ & $12 / 15$ & $12 / 15$ \\
\hline Amel. & $X / Y$ & $X / Y$ & $X / Y$ & $X / Y$ \\
\hline D5S818 & $12 / 12$ & $12 / 12$ & $12 / 13$ & $12 / 13$ \\
\hline FGA & $22 / 25$ & $22 / 25(33.2)$ & $20 / 24$ & $20 / 24$ \\
\hline
\end{tabular}

cartridge inside. Furthermore, the gunshot residue test carried out on the murderer's hands was positive.

The study of the wounds allowed the reconstruction of the bullet trajectories: The first shot was fired from below to above, from back to front, and from right to left (entrance hole on the right dorsal region with inverted edges, surrounded by excoriation; exit hole on the 4th left intercostal space, with everted edges and absence of excoriations, larger than the first one). The second shot was fired from the top down, from front to back, and from left to right (entrance hole on the left upper abdominal quadrant with inverted edges, surrounded by excoriation; with the bullet retained in right gluteal region). The macroscopic and microscopic characteristics (negativity of the coloration with sodium rhodizonate) of the entry hole established that the firing distance was greater than $40 \mathrm{~cm}$, according to the statement of the murderer.

\section{Toxicological analysis}

In order to check for the presence of drugs (such as cocaine, cannabinoids, methadone, and amphetamine) or alcohol, a toxicological examination was performed both on the victim's and murderer's samples (urine and blood). Toxicological examinations of the autopsy samples showed negative results concerning routinely checked substances such as opiates, amphetamines, benzodiazepines, cannabinoids, antidepressants, and cocaine. Alcohol was also negative. Moreover, the same toxicological examinations on the murderer's urine and blood were also negative.
At the end of the investigations, combining all "puzzle cards," the Court decided to acquit the man based on self-defense. Indeed, the forensic examination and other evidence (such as genetic analysis, toxicological and ballistic examinations) confirmed the statements of the murderer.

\section{Discussion}

Frequently, several crimes are classified as "cold cases" because they remain unsolved, with the suspect being acquitted; on the contrary, other cases are erroneously solved by mistake; thus, innocent subjects are condemned. These two undesirable situations could be a severe consequence of loss of evidence during the criminal investigation.

A successful crime scene investigation starts with a correct analysis of the crime scene. A good crime scene investigation must be logical, scientific, and methodic. The goal of a systematic approach is to optimize the identification and collection of evidence and to minimize mistakes (Baxter Jr 2015). The first step of this process consists in making the involved area safe. This is important to prevent the destruction and contamination of evidence. The examiner must make a careful inspection of the scene, to formulate a first rough supposition about the dynamics of the events (Rudin and Inman 2000). This is a crucial phase that influences the following examiner's decision about which traces must be collected. For this reason, during this period, the investigator must be neutral; he has to analyze all the statements and take 
into account all possible theories, but he will rely exclusively on scientific evidence. The following purpose of the examiner is to document permanently the scene. This is a crucial aspect of the entire process, as it ensures that all the information will be available in succeeding investigations. It is essential to write detailed notes and observations to provide an accurate record of events (including drawings that support the report) and to capture the scene with photographs. All these recording procedures integrate with others (Miller and Massey 2016). Another important task of crime scene investigators is to collect, preserve, and analyze all evidence in an efficient way, in order to avoid sample contamination or degradation. It is very important that everyone involved in the crime scene investigation and in the processing of samples wear sterile protective garments since normal clothing can carry DNA derived from epithelial cells (Verdon et al. 2014a; Hess and Haas 2017). In the discussed case, all recommendations to avoid crime scene contamination were respected; for example, the samples were collected wearing protective suits and sterile latex gloves; in addition, every sample was kept in a different paper envelopes, as plastic can induce the formation of humidity that could alter biological traces, especially if these are not dry.

In complex criminal cases, in addition to the pathologist's analysis, the involvement of other figures who can play a pivot role is mandatory.

In the present case, the involvement of the K-9 unit was essential to solve the case. In many countries, trained dogs are used in the forensic field to identify scents left by criminals on the crime scene, thanks to their sensitive olfactory system (Schoon 2005). Trained dogs can identify odors covered by other strong odors (Kalmus 1955) and are able to recognize odors coming from different parts of the body of the same person (Settle et al. 1994). In the present case, according to the first crime scene examination and the statement of the victim's relatives, the investigations were moving towards an excess of self-defense. Therefore, the K-9 unit was needed to find the golf club used by the victim to attack the murderer. Dogs were able to identify the item by smelling the odor of the blood present on the golf club, thanks to the specific training to recognize and follow the trail of human blood (Riezzo et al. 2014; Rendine et al. 2018). After the discovery of the golf club, further investigations were made, thanks to the two different types of genetic analysis. Touch DNA was obtained from the epithelial cells left on the handled object (van Oorschot et al. 2019). The difficulty in the extraction of this type of DNA is due to its invisibility and to the fact that it is usually present in small quantities on these items (Verdon et al. 2014b). There are different techniques to obtain touch DNA, each one appropriate to the object on which DNA must be sampled (Meakin and Jamieson 2013).

In this case, the adhesive tape method was used to collect the sample from the grip of the golf club. Even if this technique is quick and straightforward, to date, according to Forsberg et al. (2016), this type of DNA extraction needs some shrewdness. Indeed, in order to obtain enough DNA, the prolongation of the overnight incubation at $56^{\circ} \mathrm{C}$ and a constant mixing of the samples were applied.

The discovery of "touch DNA" has broadened the investigators' horizon since it is possible to obtain genetic profiles from a crime scene in the absence of biological fluids. The genetic profile derived from "touch DNA" was compared and matched with the reference profile of the victim, obtained from spleen tissue. Furthermore, the DNA obtained from the blood present on the head of the golf club matched the DNA extrapolated from a buccal swab of the murderer.

The combination of all this evidence led to the reconstruction of the dynamics, confirming the statements of the murderer; thus, helping the judge in making the judgment of acquittal: it was self-defense.

\section{Conclusion}

This study provides some insights on the importance of "touch DNA" and on the techniques used to recover this particular trace DNA. This kind of evidence is very useful in a wide range of criminal investigations ranging from theft and sexual violence to murder. In the presented case, the possibility to identify the last handler of the golf club grip was very useful for the investigation.

Moreover, the role of the K-9 unit is highlighted as an indispensable tool for crime scene investigation, particularly in those cases where important evidence could be concealed. Indeed, as discussed in this paper, in similar cases, without the presence of this support, evidence identification was very difficult, as well as the subsequent reconstruction of the events.

Finally, for these several reasons, this case report shows that in complex criminal cases the use of a multidisciplinary approach is mandatory. This has to involve different specialists, depending on the cases, to guarantee a complete and correct scientific evaluation to support the investigation.

\section{Abbreviation \\ K-9(canine): Units}

\section{Acknowledgements}

The authors thank the Scientific Bureau of the University of Catania for language support.

Funding

The authors received no specific funding for this work. 


\section{Availability of data and materials}

All data and materials used during this study are included in this article.

\section{Authors' contributions}

MF, FS, MR, LS, SD, IR, PR, NP, MS, GB, and FM have participated actively to solve the case. FS, MR, IR, NP, and GB carried out the experiments. MF, LS, SD, PR, MS, and FM contributed to the interpretation of the results. MF, FS, GB, and FM wrote the manuscript in consultation with MS, IR, and PR. All authors provided critical feedback and helped shape the analysis and manuscript. All authors read and approved the final manuscript.

\section{Ethics approval and consent to participate}

All procedures performed in the study were in accordance with the ethical standards of the institution and with the 1964 Helsinki Declaration and its later amendments or comparable ethical standards. Informed consent was obtained from the relatives.

\section{Consent for publication}

The authors declare to have received written consent from relatives of all persons involved in this case report, to publish the article mentioned above in Egyptian Journal of Forensic Sciences.

\section{Competing interests}

The authors declare that they have no competing interests.

\section{Publisher's Note}

Springer Nature remains neutral with regard to jurisdictional claims in published maps and institutional affiliations.

\section{Author details}

'Department of Clinical and Experimental Medicine, Section of Legal Medicine, University of Foggia, Viale Pinto, 71122 Foggia, Italy. ${ }^{2}$ Institute of Legal Medicine, Universita degli studi Magna Graecia di Catanzaro, Catanzaro, Italy. ${ }^{3}$ Department of Medical and Surgical Sciences and Advanced Technologies GF Ingrassia, University of Catania, Catania, Italy.

Received: 6 December 2018 Accepted: 4 March 2019

Published online: 11 March 2019

\section{References}

Baxter E Jr (2015) Complete crime scene investigation handbook. 1st edn, Boca Raton, CRC Press, p. 1-610, eBook ISBN9781498701457, https://doi.org/10. 1201/b18329, SubjectsSocial Sciences, Available to: https://www.crcpress. com/Complete-Crime-Scene-Investigation-Handbook/Baxter-Jr/p/book/ 9781498701440

Bilge Y, Kedici PS, Alakoç YD, Ülküer KÜ, Ilkyaz YY (2003) The identification of a dismembered human body: a multidisciplinary approach. Forensic Sci Int 137(2-3):141-146. https://doi.org/10.1016/S0379-0738(03)00334-7

Butler JM (2011) Advanced topics in forensic DNA typing: methodology. Academic, London

Cablk ME, Sagebiel JC (2011) Field capability of dogs to locate individual human teeth. J Forensic Sci 56(4):1018-1024. https://doi.org/10.1111/j.1556-4029. 2011.01785.x

Cafarelli FP, Grilli G, Zizzo G et al (2018) Postmortem imaging: an update. Semin Ultrasound CT MRI. https://doi.org/10.1053/j.sult.2018.10.012

DeGreeff LE, Weakley-Jones B, Furton KG (2012) Creation of training aids for human remains detection canines utilizing a non-contact, dynamic airflow volatile concentration technique. Forensic Sci Int 217(1-3):32-38. https://doi. org/10.1016/j.forsciint.2011.09.023

Forsberg C, Jansson L, Ansell R, Hedman J (2016) High-throughput DNA extraction of forensic adhesive tapes. Forensic Sci Int Genet. 24:158-163. https://doi.org/10.1016/j.fsigen.2016.06.004

Harding BE, Sullivan LM, Adams S, Middleberg RA, Wolf BC (2011) Multidisciplinary investigation of an unusual apparent homicide/suicide. Am J Forensic Med Pathol 32(3):208-212. https://doi.org/10.1097/PAF. 0b013e318221ba71

Hess S, Haas C (2017) Recovery of trace DNA on clothing: a comparison of minitape lifting and three other forensic evidence collection techniques. Forensic Sci 62(1):187-191. https://doi.org/10.1111/1556-4029.13246
Kahana T, Penner M, Nachman R, Hiss J (2005) Multidisciplinary forensic approach-investigation of a neonaticide and alleged concomitant rape. J Clin Forensic Med 12(3):143-148. https://doi.org/10.1016/j.jcfm.2004.11.002

Kalmus $H$ (1955) The discrimination by the nose of the dog of individual human odours and in particular of the odours of twins. Br J Anim Behav 3(1):25-31. https://doi.org/10.1016/S0950-5601(55)80072-X

Komar D (1999) The use of cadaver dogs in locating scattered, scavenged human remains: preliminary field test results. J Forensic Sci 44(2):405-408

Lorenzo N, Wan T, Harper RJ et al (2003) Laboratory and field experiments used to identify Canis lupus var. familiaris active odor signature chemicals from drugs, explosives, and humans. Anal Bioanal Chem 376(8):1212-1224. https:// doi.org/10.1007/s00216-003-2018-7

Maglietta F, Sessa F, Albano GD et al (2017) Italian Mafia: a focus on Apulia Mafia with a literature review. Acta Medica Mediterr. (6):947-952. https://doi.org/10. 19193/0393-6384_2017_6_149

Marchal S, Bregeras O, Puaux D, Gervais R, Ferry B (2016) Rigorous training of dogs leads to high accuracy in human scent matching-to-sample performance. PLoS One 11(2). https://doi.org/10.1371/journal.pone.0146963

McEwen BJ, McDonough SP (2016) Domestic dogs (Canis lupus familiaris) and forensic practice. Forensic Sci Med Pathol 12(4):530-531. https://doi.org/10. 1007/s12024-016-9808-7

Meakin G, Jamieson A (2013) DNA transfer: review and implications for casework. Forensic Sci Int Genet 7(4):434-443. https://doi.org/10.1016/j.fsigen.2013.03.013

Miller MT, Massey P (2016) The crime scene: a visual guide. 1st edn. eBook ISBN: 9780128013588, Paperback ISBN: 9780128012451, Academic Press, p. 1-302, Available to: https://www.elsevier.com/books/the-crime-scene/miller/978-012-801245-1

Pomara C, Gianpaolo DP, Monica S et al (2015) "Lupara Bianca" a way to hide cadavers after Mafia homicides. A cemetery of Italian Mafia. A case study. Legal Med 17(3):192-197. https://doi.org/10.1016/j.legalmed.2014.12.008

Rendine M, Fiore C, Bertozzi G et al (2018) Decomposing human blood: canine detection odor signature and volatile organic compounds. J Forensic Sci. https://doi.org/10.1111/1556-4029.13901

Riezzo I, Neri M, Rendine M et al (2014) Cadaver dogs: unscientific myth or reliable biological devices? Forensic Sci Int 244:213-221. https://doi.org/10. 1016/j.forsciint.2014.08.026

Rudin N Inman K (2000) Principles and practice of criminalistics: the profession of forensic science. 1st edn, CRC Press, p. 1-392, ISBN 9780849381270 - CAT\# 8127, Series: Protocols in Forensic Science, Available to: https://www.crcpress. com/Principles-and-Practice-of-Criminalistics-The-Profession-of-ForensicScience/Inman-Rudin/p/book/9780849381270

Schoon GAA (2005) The effect of the ageing of crime scene objects on the results of scent identification line-ups using trained dogs. Forensic Sci Int 147(1):43-47. https://doi.org/10.1016/j.forsciint.2004.04.080

Sessa F, Franco S, Picciocchi E et al (2018) Forensic considerations on violent parasomnias during lifespan. Acta Medica Mediterr 34(Special Is):2135-2142. https://doi.org/10.19193/0393-6384-2018-4s-328

Settle RH, Sommerville BA, McCormick J, Broom DM (1994) Human scent matching using specially trained dogs. Anim Behav 48(6):1443-1448. https:// doi.org/10.1006/anbe.1994.1380

van Oorschot RAH, Szkuta B, Meakin GE, Kokshoorn B, Goray M (2019) DNA transfer in forensic science: a review. Forensic Sci Int Genet. 38:140-166. https://doi.org/10.1016/j.fsigen.2018.10.014

Verdon TJ, Mitchell RJ, van Oorschot RAH (2014a) Swabs as DNA collection devices for sampling different biological materials from different substrates. J Forensic Sci 59(4):1080-1089. https://doi.org/10.1111/1556-4029.12427

Verdon TJ, Mitchell RJ, Van Oorschot RAH (2014b) Evaluation of tapelifting as a collection method for touch DNA. Forensic Sci Int Genet. 8(1):179-186. https://doi.org/10.1016/j.fsigen.2013.09.005 